\title{
A constelação da maternidade na gestação adolescente: um estudo de casos
}

\author{
Letícia Wilke Franco Martins ${ }^{\text {a }}$, Giana Bitencourt Frizzo a , Angela Maria Polgati Diehl ${ }^{\text {b }}$ \\ a Universidade Federal do Rio Grande do Sul, Porto Alegre, RS, Brasil \\ ${ }^{b}$ Hospital Materno Infantil Presidente Vargas, Secretaria Municipal de Saúde de Porto Alegre, Porto Alegre, RS, Brasil
}

\begin{abstract}
Resumo: 0 objetivo deste estudo foi investigar a constelação da maternidade no contexto da gravidez na adolescência. Foi utilizado um delineamento de estudo de caso coletivo, com a participação de três adolescentes grávidas, primíparas, que estavam no terceiro trimestre da gestação. Foi realizada uma análise de conteúdo qualitativa das entrevistas e os dados foram categorizados seguindo os quatro temas da constelação da maternidade: vidacrescimento, relacionar-se primário, matriz de apoio e reorganização da identidade. Por serem gestantes, as questões do tema relacionar-se primário apareceram fortemente ligadas às suas expectativas em relação à maternidade e ao bebê, porém algumas participantes demonstraram dificuldades em criar tais expectativas. A diferença mais marcante da constelação da maternidade entre as gestantes adolescentes se deu no tema da reorganização da identidade, no qual os aspectos mais salientados se referiram a uma reorganização e busca da identidade adolescente concomitante à passagem para o mundo adulto.

Palavras-chave: Gravidez na adolescência, maternidade, estudo de caso.
\end{abstract}

\section{Introdução}

A gravidez na adolescência é considerada um problema de saúde pública no Brasil e em outros países do mundo (Baron et al., 2001; Benincasa, Rezende, \& Coniaric, 2008; Chalem et al., 2007; Cunnington, 2001; Ximenes Neto, Dias, Rocha, \& Cunha, 2007). O número elevado de gestações na adolescência começou a provocar um maior interesse por parte dos profissionais de saúde brasileiros (Dadoorian, 2003), principalmente porque as repercussões de uma gravidez nesse período da vida podem ser físicas, emocionais e socioeconômicas (Lage, 2008).

Na necessidade de compreensão do fenômeno, percebe-se que a experiência subjetiva de ser mãe adolescente é de fundamental importância, e a constelação da maternidade (Stern, 1997) é um conceito que traz subsídios para a compreensão dos aspectos emocionais e subjetivos da maternidade. Nesse sentido, o presente estudo buscou investigar o conceito de constelação da maternidade no contexto da gravidez na adolescência.

Assim como a adolescência, a gestação é um evento do ciclo de vida que implica uma série de mudanças, tanto biológicas como psicológicas e sociais. Além disso, constitui uma etapa de reestruturações na vida da mulher e nos papéis que ela exerce (Piccinini, Lopes, Gomes, \& De Nardi, 2008; Stern, 1997), acarretando alterações intra e interpessoais de cada membro da "família grávida" (Maldonado, 1989). Mas, quando adolescência e gestação se sobrepõem, há aspectos específicos que devem ser considerados, já que implicam em novas demandas para a adolescente e sua família, além das que são próprias da

* Autor correspondente: leticiawfranco@gmail.com adolescência (Levandowski, Piccinini, \& Lopes, 2008). Autores clássicos, tanto da psicanálise como da psicologia do desenvolvimento (Blos, 1994, 1996; Inhelder \& Piaget, 1976; Knobel, 1981), escreveram sobre as demandas específicas do adolescente.

Knobel (1981) estava interessado em compreender a "adolescência normal", ou seja, os fatores comuns da adolescência. A busca de si mesmo e da identidade, a necessidade de se integrar a grupos, a atitude social reivindicatória e o desenvolvimento da sexualidade (saindo do autoerotismo para práticas de genitalidade) são algumas das características. Nesta etapa da vida, o adolescente $\mathrm{e} o$ adulto passam a se assemelhar sexualmente e o fim sexual (prazer e procriação) já pode ser o mesmo. Dessa forma, pode-se entender que usar a genitalidade para a procriação é um feito que causa uma modificação importante no processo de conquista da identidade adulta. Entretanto, isso também mostra a instabilidade da identidade adolescente, que ainda está reelaborando as etapas passadas da evolução libidinal (Knobel, 1981). É esperado que todo esse processo aconteça para que, então, o adolescente alcance uma personalidade mais ou menos definida e, assim, chegue ao processo de individuação, que Knobel (1981), bem como Blos (1994, 1996), considera uma das funções essenciais da adolescência.

A formação da identidade adolescente também se caracteriza pela mudança da forma que o indivíduo se relaciona com seus pais. Numa perspectiva psicanalítica, as figuras parentais já estariam internalizadas à personalidade do adolescente, e assim ele pode realizar esse processo de individualização (Knobel, 1981). Ao encontro dessa assinalação, Blos $(1994,1996)$ propõe que compreendamos a adolescência como o segundo processo 
de individuação. Dessa maneira, esse período implicaria tanto na perda de laços com objetos infantis como em alcançar uma maior independência familiar, tornando o indivíduo um membro da sociedade e também do mundo adulto. Esse processo promoveria, inclusive, a possibilidade da formação de seu próprio grupo familiar (Blos, 1994, 1996).

Por sua vez, Colarusso (1990) propõe que, entre o final da adolescência e a adultez jovem, ocorreria a transição da segunda individuação para a terceira. Esse processo também envolveria a capacidade de separação dos objetos infantis, mas agora auxiliando no engajamento em tarefas específicas da fase da adultez jovem, como, por exemplo, a independência financeira em relação aos pais e a preparação para a carreira profissional. Mais cedo ou mais tarde, esse jovem adulto poderia constituir família, preenchendo o vazio intrapsíquico deixado pela separação dos objetos infantis (Colarusso, 1990). Considerar essa transição da segunda para a terceira individuação é importante para a compreender a gravidez na adolescência. Estudos (Freitas, 2013; Levandowski, Piccinini e Lopes, 2009) vêm mostrando a presença, nesse contexto, tanto de características da segunda individuação quanto da terceira individuação.

Uma das razões que dificultaria o processo de tornar-se mãe na adolescência seria o fato de que uma gravidez nesse período poderia aumentar a turbulência já característica da adolescência, considerando que haverá uma sobreposição de tarefas desenvolvimentais. Porém, alguns autores (Brückner, Martin, \& Bearman, 2004; Flanagan, McGrath, Meyer, \& Coll, 1995) mostraram a variabilidade entre as mães adolescentes quanto ao seu próprio desenvolvimento e à sua compreensão do papel materno, já que unicamente a idade cronológica da mãe parece pouco informar sobre suas capacidades de exercer a maternidade. Tal discussão também remete a pensar que a maternidade por si só não confere o status de adulta à mãe adolescente.

A sociedade, conhecendo apenas alguns aspectos sobre a gravidez adolescente, retrata-a como algo que repercute inevitavelmente de forma negativa na vida da jovem mãe, estando muito vinculado, no imaginário social, a famílias de poucas condições educacionais, sociais e econômicas (Esteves \& Menandro, 2005). Porém, estudos indicam que a visão da adolescente sobre sua gravidez é a de que nem sempre a gravidez na adolescência é um problema ou é indesejada (Pariz, Mengarda, \& Frizzo, 2012) e que ocorrem repercussões de diversas modalidades nas vidas de mulheres que engravidaram na adolescência, e que nem sempre foram negativas e limitantes (Esteves \& Menandro, 2005), apesar dos pais da adolescente verem tal fato como um problema (Pariz et al., 2012).

Estudos também vêm mostrando que apesar das mães da adolescente ficarem, no início, descontentes com a notícia da gravidez, após o choque incial aceitam apoiar a filha durante a gestação (Fernandes, Santos-Júnior \& Gualda, 2012). Tal conduta pode estar relacionada ao fato de muitas delas também terem sido mães na adolescência (Fernandes et al., 2012; Frizzo et al., 2005).
Sabe-se que o relacionamento da nova mãe com sua própria mãe passa por uma reativação e reorganização na gravidez, momento em que é necessária a formação de modelos de maternagem, positivos ou negativos (Cramer \& Palacio-Espasa, 1993; Klaus et al., 2000; Maldonado, 1989; Stern, 1997). Assim, a relação da nova mãe com a experiência de ter sido cuidada por sua própria mãe será a maior influência sobre seu comportamento materno com seu bebê (Stern, 1997).

Stern (1997) sugere que, com o nascimento do seu filho, a mulher entra em uma organização psíquica específica, que o autor denominou constelação da maternidade. A constelação consiste em quatro temas relacionados e suas tarefas: (1) Tema de vida-crescimento, em que a questão central é se a mãe será capaz de manter o bebê vivo, de fazer ele crescer e se desenvolver; (2) Tema do relacionarse primário, que se refere à capacidade de envolvimento sócio-emocional da mãe com o bebê; (3) Tema da matriz de apoio, que se refere à necessidade da nova mãe de criar uma rede de apoio que a ajude a realizar plenamente as duas primeiras tarefas; e (4) Tema da reorganização da identidade, em que a questão é se a mãe será capaz de transformar sua autoidentidade para realizar suas funções, agora como mãe.

A constelação da maternidade se tornaria, então, o eixo organizador da vida da mulher-mãe durante meses, e até mesmo anos, sendo considerada uma organização temporária e completamente normal que acabaria por determinar uma nova série de tendências de ação, fantasias, medos, desejos e sensibilidades. Nesse período, a mulher deixaria de ter o complexo de Édipo como organizador dominante e entraria na constelação da maternidade: ao invés de ter como predominante a tríade edípica mãe/pai/bebê, a nova tríade psíquica mãe-da-mãe/mãe/ bebê passaria a existir e se tornaria o eixo organizador central (Stern, 1997). Alguns aspectos da constelação da maternidade já iniciariam na gestação ou até mesmo antes (Stern, 1997), pois seriam questões inerentes também às expectativas e desejos do tornar-se mãe. Além disso, a pré-história dessa criança que está por vir se inicia na história de cada um dos pais (Brazelton \& Cramer, 1992; Fraiberg, Adelson, \& Shapiro, 1994; Zornig, 2010) e as representações parentais acerca do bebê costumam anteceder a concepção (Stern, 1997).

Sobre esta questão, um estudo realizado na Turquia por Ilicali \& Fisek (2004) investigou representações maternas em grávidas e em mães no período pós-parto. A amostra era de 23 grávidas primíparas (entre o $4^{\circ}$ e o $7^{\circ}$ mês de gestação) e de 25 mães no período pós-parto (de zero até seis meses após o nascimento). Os achados indicaram que as representações sobre si enquanto pessoa e as representações sobre si como mãe apareciam concomitantemente e de forma integrada nesse período da gestação. Pode-se entender esse resultado a partir da colocação de Stern (1997), que mostra que a constelação da maternidade já estaria presente em algum grau durante a gravidez. Portanto, as representações da futura mãe-enquanto-mulher vão 
dando espaço para as representações da futura-mãe-enquanto-mãe. Porém, ambas as representações (e outras mais) coexistem nesse momento, já que o tornar-se mãe é um processo contínuo e complexo.

Por sua vez, um estudo italiano (Innamorati, Sarracino, \& Dazzi, 2010) teve como objetivo explorar a prevalência e o desenvolvimento da constelação da maternidade em mulheres grávidas em três períodos gestacionais: menos de seis meses, entre seis e sete meses e mais de sete meses. Os resultados indicaram que os temas da constelação são mais acentuados no período de seis a sete meses gestacionais, confirmando o que era previsto por Stern (1997): alguns aspectos da constelação já se manifestam na gravidez. Outro achado de Innamorati et al. (2010) foi de que o tema vida-crescimento foi o mais evidenciado pelas grávidas.

Um estudo brasileiro (Gabriel, Ribeiro, Vivian, \& Lopes, 2012) investigou como se dá a constelação da maternidade, na gestação do segundo filho no terceiro trimestre gestacional. Porém, por se tratar da gestação do segundo filho, os autores encontraram diferenças na forma como a constelação da maternidade se manifestou nessas gestantes: os aspectos que caracterizam o tema vida-crescimento, como o receio de não conseguir manter o bebê vivo, ou o medo do bebê não ser saudável, por exemplo, apareceram com menor intensidade na segunda gestação em comparação a outros três temas. Este resultado diverge do encontrado por Innamorati et al. (2010), todavia pode-se entender que, por essas mães já terem tido sucesso na criação do primeiro filho, superando esses medos e anseios, elas ficaram, de alguma forma, mais tranquilas em relação a sua capacidade de propiciar um desenvolvimento bom e saudável ao segundo filho.

Os achados desses estudos, além da teoria desenvolvida por Stern, ajudam a justificar a realização de pesquisas referentes à constelação da maternidade durante a gestação. Faz-se, então, interessante pesquisar como a constelação da maternidade aparece em contextos diferentes. Por esta razão, o objetivo deste estudo é investigar a constelação da maternidade no contexto da gravidez na adolescência.

\section{Método}

\section{Participantes}

Fizeram parte desse estudo três gestantes adolescentes que participam do projeto longitudinal intitulado "Aspectos Biopsicossociais da Gravidez Adolescente: Estudo Longitudinal da Gestação ao Segundo Ano de Vida da Criança (GRADO)" (Piccinini et al., 2008b), que acompanhou 180 adolescentes gestantes em Porto Alegre, Rio Grande e Santa Maria. Especificamente no centro Porto Alegre, foram acompanhadas 60 gestantes e, quando possível, seu companheiro e a avó materna do bebê também foram convidados a participar do estudo. Os critérios de inclusão para a participação no projeto foram: que as adolescentes não apresentassem intercorrências clínicas durante a gravidez, que a gravidez não fosse fruto de abuso sexual, que não tivessem comprometimento mental e emocional e que não fossem usuárias de substâncias durante a gestação.

O projeto contemplou quatro fases de coletas de dados: Fase I: terceiro trimestre da gestação; Fase II: 3 meses de vida do bebê; Fase III: 12 meses de vida do bebê; e Fase IV: 24 meses de vida do bebê. As gestantes foram selecionadas a partir do encaminhamento de hospitais públicos de Porto Alegre e de unidades básicas de saúde, e tiveram o Termo de Consentimento Livre e Esclarecido assinado pelo responsável.

Este projeto seguiu os princípios éticos da pesquisa que dizem respeito à proteção dos direitos, bem-estar e dignidade dos participantes, como destacado pela resolução 196/96 do Conselho Nacional de Saúde. Também foi aprovado por diversos Comitês de Ética em Pesquisa (processos $n^{\circ} 25000.089325 / 2006-58$ - UFRGS e processo $n^{\circ}$ 20/08 - Hospital Materno-Infantil Presidente Vargas).

Para fins do presente estudo, foram analisados os dados das três primeiras gestantes adolescentes do centro Porto Alegre que completaram a Fase I da pesquisa. Todas aceitaram a gravidez e eram filhas de mães que também engravidaram na adolescência.

\section{Delineamento, instrumentos e procedimentos}

Um delineamento de estudo de caso coletivo (Stake, 1994) foi utilizado a fim de investigar como se dá a no constelação da maternidade contexto da gravidez na adolescência.

Foi realizada com as gestantes a "Entrevista sobre a maternidade adolescente - terceiro trimestre da gestação" (NUDIF/UFRGS, 2008a), a fim de investigar as percepções da gestante no que se refere à sua gravidez e às suas expectativas quanto ao futuro bebê. Também se aplicou a "Entrevista de dados sócio-demográficos" (NUDIF/ UFRGS, 2008b) para a descrição dos casos. Ambas foram gravadas em áudio e transcritas.

\section{Análise dos dados}

As entrevistas foram gravadas e transcritas e os dados coletados das entrevistas foram tratados por análise de conteúdo (Bardin, 1977; Laville \& Dionne, 1999), com ajuda do software Nvivo.

As categorias de análise foram definidas a partir dos temas da constelação da maternidade de Stern (1997). A definição operacional das categorias foi baseada na obra de Stern (1997) e nos artigos de Gabriel et al. (2012) e Innamorati et al. (2010) para as especificidades da constelação da maternidade na gestação:

1- Vida-crescimento: Essa categoria abarca as preocupações da jovem mãe em relação à sua competência em garantir o desenvolvimento e sobrevivência do bebê. Entre as preocupações maternas estão o medo de possíveis 
malformações do bebê que ainda está em sua barriga, o medo de abortos, além do temor de haver problemas no parto.

2- Relacionar-se primário: Essa categoria se refere ao envolvimento sócio-emocional da díade mãe-bebê, o que se refere ao apego, afeição, sentimento de segurança, à regulação do ritmo do bebê, à capacidade de holding e à indução e instrução nas regras que regem uma relação humana. Envolve os medos de não conseguir ser uma mãe afetuosa e cuidadosa, de não se sentir natural no exercício da maternidade e de não conseguir amar o seu filho.

3- Matriz de apoio: Refere-se à necessidade que a mãe tem de criar, permitir, aceitar e regular uma rede de apoio que seja protetora, ajudando a mãe a realizar de forma plena as tarefas do tema vida-crescimento e do relacionar-se primário.

4- Reorganização da identidade: Necessidade da mãe de transformar e reorganizar sua própria identidade, redefinindo as prioridades do novo papel que virá a assumir.

\section{Resultados}

Os resultados da pesquisa foram expostos em cada caso separadamente, a partir das categorias descritas acima. As categorias foram exemplificadas com alguns trechos das entrevistas realizadas com as mães, tendo os nomes substituídos por nomes fictícios. Ao final de cada um dos casos, encontra-se um entendimento dinâmico da constelação da maternidade na gestação no caso estudado. Após a exposição dos três casos, foram discutidas as semelhanças e diferenças entre eles, a fim de investigar como se deu a constelação da maternidade no contexto da gravidez na adolescência.

\section{Caso 1: Thaís}

Thaís era uma adolescente de 17 anos que se encontrava no terceiro trimestre da gestação de Patrick, seu primeiro filho. Thaís não trabalhava. Ela estava com a faculdade trancada porque estava repensando o seu curso de graduação. Thaís e Vitório (21 anos) namoravam há três anos e moravam juntos há dois. Vitório fazia estágio em um órgão público e cursava o Ensino Técnico. O casal vivia com o salário de Vitório e com a pensão do pai de Thaís. A notícia da gravidez foi recebida com surpresa, pois não a estavam planejando para esse momento, mas a aceitaram. A mãe de Thaís morava com o casal, mas estava com mudança marcada para uma cidade a $150 \mathrm{~km}$ de Porto Alegre.

Vida-crescimento - Thaís

Thaís relatou que estava com medo em relação ao parto, que poderia não sair conforme o planejado: "Não tem porque eu não ganhar de parto normal, só se não der mesmo, mas cesárea eu não quero fazer de jeito nenhum". A adolescente revelou que o medo maior da cesárea era motivado por um caso de recuperação difícil de cesárea em sua família, e também pelo fato de que sua mãe iria se mudar.

Thaís relatou que vinha tendo preocupações em relação às suas competências no cuidado de Patrick, quando ele nascesse: "Eu tenho preocupação em relação à febre, essas coisas assim, banho ... Tenho medo de, de repente, deixar escorregar e cair dentro d'água, eu sou muito desastrada". A jovem mãe também se referiu ao medo de que o seu bebê tivesse alguma enfermidade.

\section{Relacionar-se primário - Thaís}

Quando questionada sobre como imaginava que seria o seu relacionamento com seu bebê, Thaís se referiu às necessidades básicas dele: "Eu acho que vai ser bom porque nos primeiros seis meses é quando o bebê mais precisa da mãe". Quando solicitado que falasse mais sobre o relacionamento dos dois, disse que não saberia dizer, "só vendo depois né".

Matriz de apoio - Thaís

Thaís se referiu bastante ao quanto Vitório a estava apoiando, por exemplo, indo nas consultas. Além disso, ela comentou que Vitório a apoiava também emocionalmente: "Eu tenho recebido bastante [apoio de Vitório]. Eu converso bastante com ele em relação ao que eu sinto. . . . Eu podia ta entrando em depressão se eu não tivesse ninguém do meu lado. E ele é a pessoa que mais tá do meu lado agora". Thaís também estava recebendo apoio da sogra durante a gestação, tanto para acalmar seus medos do parto como dos cuidados com a criança. Por sua vez, o pai de Thaís ajudava em termos financeiros. Segundo ela, sua mãe a apoiava no sentido de conversar e tirar dúvidas.

Acerca do apoio após o nascimento de Patrick, Thaís acreditava que quem mais a ajudaria seria sua sogra, já que sua mãe iria embora: "Como ela (mãe) vai embora, quem vai me ajudar mais é a minha sogra. Quando eu sair pra trabalhar, não tenho com quem deixar, mas ai perto de casa tem a minha vó, os meus tios. Eu sei que elas vão me ajudar bastante".

\section{Reorganização da identidade - Thaís}

Quando questionada sobre o que mudou em sua vida em função da gravidez, Thaís respondeu o seguinte: "Ah, o meu jeito de pensar, em relação a cuidar de casa, ter um compromisso, mudou bastante, porque antes era só a minha mãe pra cuidar da casa". Thaís atribuía essa mudança ao fato de ter começado a morar junto com Vitório e agora precisar organizar a casa e as coisas dos dois.

Thaís também se referiu às mudanças com relação às roupas que passou a usar na gravidez e aos lugares que deixou de frequentar: "A única coisa assim é eu sair pra festa . . começou ficando mais complicado, lugar muito cheio, abafado, ... ai ficava ruim. Outra coisa que mudou 
bastante foi em relação à roupa. Eu só usava calça jeans, agora não posso usar mais".

\section{A constelação da maternidade na gestação de Thaís}

Pode-se identificar a presença dos temas da constelação da maternidade na gravidez de Thaís. O fato de que sua mãe não estaria presente no pós-parto configura uma questão bastante especial, que influencia aspectos da constelação. Thaís já esperava não poder contar com sua mãe na sua matriz de apoio após o nascimento de Patrick. Além disso, os medos relacionados à recuperação do parto, se fizer uma cesárea, parecem estar associados ao fato de que sua mãe não estaria presente para cuidá-la. Outro fator importante a ser analisado é o fato de Thaís não ter se referido, na sua reorganização da identidade, à transposição de filha para mãe, somente a de adolescente-sem-compromissos para esposa e dona de casa. Talvez se deva ao fato de ela ter dificuldade de se imaginar como mãe antes de ganhar o filho.

\section{Caso 2: Camile}

Camile tinha 16 anos e estava no terceiro trimestre da gestação de Thomas, seu primeiro filho. Camile não esperava engravidar nesse momento, mas ela e o namorado, Davi (32 anos), aceitaram a gravidez. Camile estava cursando a $7^{\mathrm{a}}$ série de uma escola pública de Porto Alegre e não trabalhava, somente recebia uma pensão de seu pai na época da entrevista. Ela revezava a moradia entre a casa da sua mãe e a de Davi, que morava sozinho. Davi e Camile tinham um relacionamento sério há um ano e seis meses, mas ela não pensava em se casar com ele. Davi parou de estudar na $8^{a}$ série porque precisava trabalhar. Na época da entrevista, trabalhava em uma empresa localizada em uma cidade vizinha a Porto Alegre.

Vida-crescimento - Camile

Camile se referiu, primeiramente, ao medo em relação à sua capacidade de cuidar do seu bebê: "Ah, no começo é sempre difícil, que tu não sabe o que tu vai fazer ou como é que vai ser, ... ai tu fica sempre com aquele medo de, será que eu vou saber cuidar da criança, sendo adolescente sabe?".

Camile relatou preocupações que vieram com o terceiro trimestre da gravidez: "Quando chega no final, a gente fica meio preocupada né, de como é que vai ser, se tu vai ter algum problema". Também houve referências à preocupação de o parto não ser conforme o planejado: "Eu nunca quis fazer cesárea, nunca. . . Eu morro de medo que os médicos tenham que olhar pra minha cara e dizer que eu vou ter uma cesárea". Também citou preocupações quanto à amamentação: "Vai ser dificil dar mama . . . tu fica naquela preocupação ... e se a criança se afogar, se a criança começar a tossir, o que eu vou fazer?". A adolescente se referiu ao desejo de que o nascimento do filho ocorresse logo, mas, ao mesmo tempo, vinham as preocupações quanto às condutas na maternidade: "tu fica com aquela ansiedade que nasça de uma vez, mas quando nasce tu diz: 'o que que eu vou fazer?' Se quando a criança chora, o que eu vou fazer".

\section{Relacionar-se primário - Camile}

Acerca do relacionamento com seu filho, Camile diz: "Não sei, eu não parei pra pensar". E não conseguiu produzir mais nada neste sentido.

\section{Matriz de apoio - Camile}

No período da gravidez, Camile estava contando com a ajuda da mãe, mas achava que a mãe a ajudava pouco, não conversavam muito, somente sobre os mesmos assuntos: trabalho da mãe e consultas médicas de Camile. "Quando eu preciso de alguma coisa, ela vai lá e me ajuda, se eu tenho que botar uma roupa, ... me abaixar pra botar um tênis, ... a ai ela coloca, tenta me ajudar de tudo que é jeito". Por sua vez, seu pai vinha ajudando no sentido de poupar a filha do cansaço: "Às vezes quando eu tenho que ir no centro ou eu tenho que pagar alguma coisa, ele vai lá e paga pra mim... tudo pra não me cansar sabe. Então ele tem me ajudado bastante assim".

Camile também recebia o apoio de sua madrinha, com quem conversava muito. Ela também vinha recebendo apoio dos colegas do colégio, que aprenderam a fazer sapatinhos de lã e outras coisas para presenteá-la. "Eles se juntaram lá na turma, tão aprendendo a fazer crochê, todo final de semana. .. e essa semana foram levar doze sapatinhos de lã".

Camile não falou nada sobre como ela imaginava que seria sua matriz de apoio após o nascimento de Thomas.

\section{Reorganização da identidade - Camile}

Camile falou sobre as mudanças que a gravidez já estava impondo à sua vida de adolescente:

Na questão física . . . tu adolescente usa aquelas roupas loucas, tudo curto, aí depois começou a mudar ... ai tinha que andar com as coisas mais leves, e na questão emocional. . . tu tá saindo pra festa ... tá jogando bola. É bem difícil tu parar assim um tempo.

Camile também observou mudanças nos olhares das outras pessoas em relação a ela:

As pessoas não te olham mais como tu era antes. Eu sempre fui assim elétrica, então todo mundo me olha assim e me acha meio quieta e "ah, tu tá diferente" ... é que tu muda, tu começa a pensar mais na criança, ... e acaba esquecendo um pouco de ti. 
Camile também observou essas mudanças na sua relação com as suas colegas do colégio, que nesse momento a procuravam para saber como era estar grávida e para pedir conselhos quanto ao momento certo de engravidar: "Elas me olham assim como se eu fosse uma adulta".

\section{A constelação da maternidade na gravidez de Camile}

Aspectos da constelação da maternidade também foram observados na entrevista de Camile, no terceiro trimestre de sua gestação. Mas a adolescente não conseguiu desenvolver, na entrevista, as preocupações acerca do relacionar-se primário e da matriz de apoio após o nascimento de Thomas. Além disso, adolescente não se referiu a Davi em sua matriz de apoio. Ela tinha preocupações quanto à sua capacidade de cuidar de um bebê, e associava tal preocupação ao fato de ser uma adolescente. $\mathrm{O}$ tema reorganização da identidade foi percebido por ela em aspectos como o modo de se vestir grávida versus modo de se vestir adolescente. Ela também chamava atenção para a forma como as outras pessoas a enxergavam e o que esperavam dela. Além disso, admitiu que mudou, passando a pensar mais no bebê, marcando o início do tornar-se mãe, mesmo ainda na gestação.

\section{Caso 3: Giulia}

Giulia, uma adolescente de 15 anos, estava no terceiro trimestre de gestação da Cristina Luísa, primeira filha de Giulia e de seu namorado Edson (19 anos). Eles namoravam há um ano e moravam juntos há oito meses no momento da entrevista. Giulia relatou ambivalência sobre querer engravidar, pois a casa dela e de Edson ainda não estava pronta, mas, por outro lado, pensava já estar se relacionando com Edson há tempo suficiente, além de conhecer outras meninas que estavam grávidas, entre elas sua irmã. Giulia cursava a $6^{\mathrm{a}}$ série do Ensino Fundamental, mas parou quando começaram os enjoos da gravidez. Não trabalhava, mas pretendia trabalhar no futuro. Edson parou de estudar no Ensino Médio para poder trabalhar. No momento, ele era responsável pelo sustento de Giulia.

Vida crescimento - Giulia

A principal preocupação de Giulia era com o parto. Preferia parto normal à cesárea. Preocupava-se com seu estado na hora do parto: "aí eu fico preocupada só de dar uma preocupação na hora né, porque nunca se sabe, a gente nunca tá pronta o suficiente". Quando questionada sobre preocupações em relação ao bebê, Giulia respondeu: "Tenho medo só de (a filha) ficar doente, com certeza, isso ai vai acontecer alguma hora, e eu não sei como é que eu vou tá preparada, porque querendo ou não, eu sou bem dizer uma criança ainda. Sei pouca coisa, eu não aprendi tudo ainda. ..". Mas Giulia também achava que "Vai ser fácil .. dar banho, cuidar" da filha e relatou que o que não soubesse poderia perguntar para pessoas mais experientes.

\section{Relacionar-se primário - Giulia}

Em relação a como Giulia imaginava que seria seu relacionamento com a filha, ela respondeu: "Eu acho que sempre procurar dar o melhor pra ela, nunca deixar ela sofrer, ter o maior cuidado possivel, porque eu tenho quinze anos recém... Acho que tenho certeza, vai ser fácil dar amor".

\section{Matriz de apoio - Giulia}

Giulia mencionou que sua mãe estava lhe ajudando muito, acompanhando tudo que a filha fazia, se preocupando com ela. Giulia relatou que vinha se sentido mais próxima de sua mãe a cada dia. Também comentou que estava muito feliz com o apoio recebido de Edson: "Eu acho que o que me dá mais força de aguentar toda hora enjoo, azia, não reclamar, . . é o lado dele. . de ele me apoiar numa hora que eu preciso, porque eu tenho quinze anos, bem dizer, eu não saberia nada, e ele tá sempre comigo". Quando tivesse alguma dificuldade nos cuidados com a filha, acreditava que pediria ajuda para a mãe e para o namorado: "dificil vai ser quando ela ficar doente, que dai com certeza, eu vou ficar nervosa naquela hora, eu vou pedir ajuda pra minha mãe, pro Edson, com certeza, eles vão me ajudar, eu não vou saber o que fazer, eu vou ficar tensa".

Giulia também tinha um padrinho que era uma pessoa muito importante para ela: "ele me acompanha nas consultas quando o Edson não pode, ele me ajuda financeiramente também, ele me ajuda emocionalmente, ele me explica tudo".

Reorganização da identidade - Giulia

Giulia não conseguiu identificar mudanças em sua vida relacionadas à gravidez, somente mencionou seus sentimentos relacionados ao fato de estar grávida: "Emocionalmente, eu me sentia eu acho que feliz pelo fato de ter uma criança que ia ser minha, que eu ia poder cuidar do jeito que eu queria, ... (Agora) continua igual, só que bem mais aflita. Não vejo a hora de ganhar de uma vez".

\section{A constelação da maternidade na gravidez de Giulia}

Foi possível identificar aspectos da constelação da maternidade na gravidez de Giulia. Uma característica importante deste caso é que Giulia apresentou sentimento de ambivalência em relação à gravidez, já que, por um lado, a desejava. Possivelmente este fato propiciou que Giulia conseguisse externalizar aspectos referentes ao relacionar-se primário, já que consegue se imaginar como mãe, conseguindo projetar que sentirá amor pela filha. Ela se remete bastante ao fato de ter 15 anos e relaciona sua idade a sentimentos de insegurança e ansiedade quanto ao nascimento e ao cuidado de Lia. Por isso, Giulia também menciona que 
pedirá auxílio de outras pessoas nas situações com as quais imagina que não conseguirá lidar facilmente.

\section{Discussão}

O presente estudo teve como objetivo investigar a constelação da maternidade no contexto da gravidez na adolescência. Encontrou-se neste estudo, assim como previsto por Stern (1997), que aspectos da constelação da maternidade já estão presentes na gestação, corroborando os estudos de Innamorati et al. (2010) e Gabriel et al. (2012). Porém, percebeu-se distinções na forma como ela se manifestou no contexto em que as participantes deste estudo se encontravam: na adolescência.

$\mathrm{Na}$ categoria vida-crescimento, destacaram-se os relatos de receios quanto à capacidade da mãe cuidar do bebê. No presente estudo, essa preocupação foi associada, pelas participantes, à pouca idade, ou à pouca experiência, ou ainda às características pessoais das participantes, corroborando o estudo de Frizzo et al. (2005) que também encontrou, nas expectativas de gestantes adolescentes, uma acentuação nas preocupações quanto ao seu desempenho enquanto mãe. Mas mães adultas também mencionam esse sentimento, segundo os achados de Piccinini et al. (2008). Portanto, tal sentimento parece estar mais associado ao fato de ser primípara, já que as mudanças são mais impactantes na primeira gestação (Klaus \& Kennel, 1992), que à adolescência da mãe. Porém, não se observou neste estudo um destaque dessa categoria em relação às outras, não corroborando os achados de Innamorati et al. (2010), que apontaram que o tema vida-crescimento apresentou-se em destaque no relato das gestantes, que eram predominantemente primíparas.

Deve-se destacar, ainda, que pelo fato de o presente estudo ter investigado a constelação da maternidade ainda na gestação, apareceu, nos três casos, o medo quanto ao parto não acontecer conforme o planejado ou contar com alguma complicação, medo não mencionado por Stern, já que ele atentou à constelação da maternidade após o nascimento do filho. Porém, o parto é antecipado, durante a gestação, sob a forma de expectativas, sendo comum que as mulheres tenham expectativas negativas frente a ele (Lopes et al., 2005). Nesse sentido, as preocupações frente ao parto podem constituir os aspectos da constelação da maternidade na gravidez, especificamente.

$\mathrm{Na}$ categoria relacionar-se primário, foram categorizadas as falas das gestantes adolescentes acerca do envolvimento sócio-emocional da díade mãe-bebê e dos medos de não conseguir ser uma mãe afetuosa ou de não se sentir natural no exercício da maternidade. Não houve falas sobre os medos relativos a esse tema, além disso, pode-se observar que foi uma categoria com poucas falas no geral. Tal achado corrobora os resultados de Piccinini et al. (2003), que revelaram que, em comparação a gestantes adultas, as gestantes adolescentes tiveram maior dificuldade em descrever suas percepções sobre seu bebê.
Pelo fato das participantes estarem grávidas, muitos aspectos da própria constelação ainda estavam permeados pelas expectativas da gestante acerca do bebê e da maternidade. Porém, em alguns casos desse estudo, pareceu haver uma falta de expectativas das mães relativas ao relacionar-se primário com seu bebê, o que é preocupante, pois as expectativas auxiliam na preparação psicológica para a maternidade e para a construção do vínculo mãe-bebê (Dirani, 1993).

Por sua vez, Giulia (caso 3) parecia já possuir há mais tempo o desejo de ser mãe - foi a única que expôs que queria a gravidez, apesar da ambivalência vivida no recebimento da notícia - e conseguiu externalizar aspectos referentes ao tema do relacionar-se primário, o que as outras participantes não conseguiram. Essa adolescente conseguiu se imaginar como mãe e expõs expectativas que ela tinha em relação ao seu bebê, se apropriando do processo de parentalidade. Afinal, muito antes da mulher ser mãe (ou do homem ser pai) as representações parentais sobre o bebê existem e já antecedem a concepção e, através de sonhos e expectativas acerca do seu desempenho enquanto mãe, a mulher vai construindo a identidade materna (Brazelton \& Cramer, 1992; Golse, 2002; Stern, 1997). Essas representações e expectativas são essenciais, no processo de tornar-se mãe, para a constituição psíquica do bebê e para o estabelecimento da relação mãe-filho. Além disso, é esperado que as representações sobre si própria enquanto pessoa e as representações sobre si própria como mãe se integrem ainda na gestação (Ilicali \& Fisek, 2004; Stern, 1997), pois a constelação da maternidade está atuando como organizador psíquico. Este investimento de expectativas e sentimentos parece importante para a constituição psíquica do bebê por possibilitar o exercício da maternidade já na gravidez (Piccinini et al., 2004).

Conforme já foi colocado, essas representações maternas se baseiam nas interações atuais, nas lembranças infantis, fantasias, medos e expectativas da mãe em relação ao bebê e em relação a ela mesma enquanto mãe (Golse, 2002; Stern, 1997). Essas representações acompanhariam a mulher desde criança e poderiam sofrer influências do contexto histórico-cultural (Dias \& Lopes, 2003) ou de uma situação psicopatológica, como a depressão pós-parto (Frizzo, Brys, Lopes, \& Piccinini, 2010; Frizzo, Prado, Linares, \& Piccinini, 2011; Schwenberger \& Piccinini, 2003; Schwengber, Prado, \& Piccinini, 2009). Estes e outros estudos realizados com mães deprimidas vêm mostrando o quanto a psicoterapia breve pais-bebê possibilita melhoras significativas nas representações negativas acerca da maternidade, corroborando as ideias de Cramer e Palacio-Espasa (1993). É possivel que tal intervenção também possa auxiliar as mães adolescentes que viessem a ter dificuldades na interação com seu bebê. Novos estudos poderiam investigar a efetividade desse modelo de intervenção nesse contexto da gestação adolescente.

A categoria matriz de apoio está relacionada à rede de apoio criada e aceita pela jovem mãe para que 
ela consiga realizar as tarefas dos dois temas anteriores. Observou-se uma prevalência das figuras femininas na matriz de apoio organizada pelas gestantes adolescentes desse estudo, especialmente a sua própria mãe.

Os resultados desse estudo corroboram a literatura (Dias \& Aquino, 2006; Frizzo et. al., 2005; Levandowski, Barth, Munhós, Rödde, \& Wendland, 2012; Lopes, Prochnow, \& Piccinini, 2010; Schwartz, Vieira, \& Geib, 2011; Stern, 1997) que aponta que o principal apoio que as mães seguem recebendo vem de uma figura feminina, na maioria dos casos sua própria mãe, sogra ou irmã mais experiente. Assim, como explicitado por Stern (1997), entende-se a importância do interesse da mãe pela sua própria mãe, já que, a partir dele, ocorre um reviver da história de identificações com essa figura materna, assim como com outras figuras de apoio (Brazelton \& Cramer, 1992; Lopes et al., 2010; Schwengber et al., 2009; Stern, 1997). Nesse período, não poucas vezes há uma reaproximação da nova mãe com sua mãe (Stern, 1997), como relatado por Giulia (caso 3) no presente estudo.

Essa mãe, nova avó, assume também o lugar, no âmbito familiar e social, de estar sempre envolvida nos cuidados com os netos (Dias \& Aquino, 2006), colocando-se como uma pessoa importante no apoio à nova mãe. $\mathrm{O}$ mesmo se aplica às sogras dessas mulheres, que agora também estão no lugar de avós (Schwartz et al., 2011).

A única adolescente que apontou a sogra como uma figura importante em sua matriz de apoio foi Thaís (caso 1), cuja mãe mudaria de cidade no seu período pós-parto. Ela contava com o apoio de sua mãe no período da gestação, mas já esperava não poder contar com tal apoio após o nascimento do filho. Além disso, os medos de Thaís com relação à recuperação do parto, caso fosse realizada cesariana, pareciam estar vinculados ao fato da mãe não poder cuidá-la, dando apoio físico e emocional nesse momento. Isso demonstra a importância atribuída a essa pessoa central: a própria mãe.

Estudos nacionais e internacionais que abordam o apoio da família apontam pais e mães da mãe adolescente como principais fontes de apoio (Bunting \& McAuley, 2004; Dias \& Aquino, 2006; Godinho, Schelp, Parada, \& Bertoncello, 2000; Miller \& Darlington, 2002). Esses estudos não dão atentam especialmente à mãe, mas sim ao casal de pais, que auxiliam as mães adolescentes a se engajaram fortemente na busca por ser boa mãe, conseguindo assumir o papel materno de forma positiva (Bunting \& McAuley, 2004).

Também se observou o pai da gestante ou uma figura masculina próxima, como um padrinho, sendo pessoas importantes no auxílio "prático" e financeiro para a gestante. Houve o relato sobre o pai ou padrinho comprar ou buscar o que a gestante necessitava. Também foi relatado o apoio emocional fornecido por essa figura masculina que não o companheiro.

Cada vez mais o companheiro, o pai do bebê, também é escalado a fazer parte dessa rede (Stern, 1997).
Algumas participantes desse estudo frisaram a importância do apoio dado por ele, corroborando os achados de Bunting $\&$ McAuley (2004) e Schwartz et al. (2011). Os resultados de Lopes et al. (2010) também corroboram a literatura, ao indicarem que a participação do companheiro em tarefas de cuidado com o bebê, apoio emocional à mãe e apoio nas tarefas domésticas são importantes para propiciar que a mulher possa tomar conta de seu filho (Cramer \& PalacioEspasa, 1993; Stern, 1997; Winnicott, 1985).

Somente uma adolescente (Camile - caso 2) não apontou o namorado, pai de seu filho, como integrante de sua rede de apoio na gestação ou quando o filho nascer. Esta adolescente também relatou não ter a intenção de casar com ele. Provavelmente ela estava tendo dificuldades em criar expectativas quanto ao namorado assumir o papel paterno, assim como o papel conjugal, não o colocando, então, na sua rede de apoio. Infelizmente, não se tem mais informações sobre a história desse casal que permitissem entender a falta de expectativas dessa jovem para com o namorado.

Portanto, o pai do bebê é uma figura importante para auxiliar a mãe com o bebê, tanto emocionalmente quanto em questões práticas (Cramer \& Palacio-Espasa, 1993; Stern, 1997; Winnicott, 1985). Porém, esse entendimento poderia ser extrapolado para o avô (pai da gestante)? E quando essa gestante é adolescente? Esse dado não foi encontrado em outros estudos ou na literatura, sendo interessante a realização de futuros estudos que investiguem qual papel o novo avô assume durante a gravidez de sua filha, seja adolescente ou adulta.

Uma participante (Camile - caso 2) relatou a participação de colegas do colégio no apoio a ela. São poucas as pesquisas sobre o apoio de outros adolescentes à mãe adolescente, porém o apoio emocional dos pares é percebido por elas como sendo importante (Bunting \& McAuley, 2004). Além disso, a revisão realizada por Bunting \& McAuley (2004) aponta que as famílias, parceiros e pares tendem a proporcionar diferentes, mas complementares, formas de apoio a mães adolescentes. Essas diferentes formas, em geral, parecem contribuir para resultados mais positivos para este grupo.

Finalmente, a categoria reorganização da identidade diz respeito à necessidade da mãe de reorganizar sua identidade. Apesar de terem aparecido algumas falas referentes a esse aspecto, verificou-se que as gestantes adolescentes participantes do presente estudo tiveram dificuldades para explanar sobre as mudanças advindas da gravidez. Ou ainda, quando conseguiam ser mais prolixas, não abordavam os temas em profundidade, sendo observada certa superficialidade nas falas.

A superficialidade observada em suas falas pode estar associada às capacidades cognitivas e emocionais próprias da adolescência, como o pensamento mágico e onipotência do adolescente (Blos, 1994, 1996; Osório, 1989; Outeiral, 1994). Nesse estágio do desenvolvimento cognitivo, o adolescente apresenta o que Inhelder e Piaget (1976) chamam de uma forma superior de egocentrismo. 
$\mathrm{O}$ adolescente procura adaptar o ambiente social ao seu eu e não o contrário. Essa característica aparece na fala de Giulia (caso 4), que quer ter um bebê que seja dela, do qual poderá cuidar do jeito que ela quiser. Nessa fala, a adolescente demonstrou dificuldade em considerar o ambiente, as normas sociais e culturais, mostrando seu pensamento egocêntrico adolescente.

Esse aspecto do desenvolvimento cognitivo pode ser relacionado à tarefa da construção da identidade, já que o adolescente está buscando o conceito de si mesmo, que remete ao conhecimento da sua individualidade enquanto ser biológico, psicológico e social no mundo que o circunda (Knobel, 1981). Portanto, ainda há um amadurecimento necessário no caminho para a maternidade. Pode-se observar essa necessidade tanto no que diz respeito ao desenvolvimento cognitivo quanto ao desenvolvimento emocional. Porém, é esperado que ocorra esse amadurecimento com o passar do tempo, já que o caminho da adolescência é chegar ao mundo adulto (Knobel, 1981).

Todavia, algumas adolescentes do presente estudo identificaram uma reorganização da identidade conforme Stern (1997) apontou, mas associada diretamente à adolescência. Por exemplo, no relato de Thaís (caso 1) apareceu a passagem de adolescente-sem-compromissos para esposa e dona de casa - não de esposa para progenitora ou de profissional para dona de casa. Ela também não se referiu à transposição de filha para mãe, o que pode ter ocorrido por ela apresentar dificuldade de se imaginar como mãe antes de ganhar o filho, conforme descrito na categoria relacionar-se primário. Outra adolescente (Camile - caso 2) também observou uma reorganização da sua identidade: de adolescente (ativa) para mãe (atenta), que passa a se preocupar mais com o bebê do que com questões pessoais ou próprias da adolescência.

Esses achados parecem mostrar que os aspectos da reorganização da identidade que ocorreriam na gravidez e maternidade adolescente podem não ser iguais àqueles descritos por Stern (1997) ao estudar mães adultas. No contexto adolescente, as questões referentes à segunda individuação (Blos, 1996) e terceira individuação (Colarusso, 1990) estariam ocorrendo simultaneamente, havendo ainda estranhamento por parte das adolescentes em ambos aspectos. Elas já abriram caminhos para novos objetos de amor e estariam fazendo o desligamento dos objetos infantis, na figura dos pais, mas ao mesmo tempo estão constituindo família e se parentalizando. Esse vazio intrapsíquico, que seria deixado pela separação dos objetos infantis, ainda não existiria completamente, porque a segunda individualização ainda estava ocorrendo. Porém, a adolescente já dispunha de um possível substituto para preenchê-lo: a nova família que estava constituindo, tarefa da terceira individuação. Os achados do presente estudo sobre a sobreposição entre tarefas da segunda e terceira individuação também foram encontrados por Freitas (2013) e Levandowski et al. (2009).

Todavia, essa sobreposição de tarefas desenvolvimentais é complexa. Talvez a dificuldade das adolescentes em falar sobre esses aspectos seja uma evidência dessa complexidade. Isso também parece deixar a adolescente confusa e impressionada com os olhares dos outros sobre elas: "elas me olham assim como se eu fosse uma adulta" (Camile - caso 2). Tal olhar e sentimento que a adolescente tem sobre estar se tornando uma adulta se relacionam à valorização da maternidade: a partir do momento que se é mãe, se assume um novo status social, o de ser mulher (Dadoorian, 1998).

Algumas adolescentes participantes desse estudo, apesar de falarem pouco, demonstraram uma satisfação com a sensação de amadurecimento advindo da gravidez. Tal achado corrobora estudos realizados com adultas (Piccinini et al., 2008) e com outras adolescentes (Amazarray et al., 1998) que também observaram esse sentimento nas mães. Os achados do presente estudo também corroboram a literatura, que entende que a gravidez pode promover crescimento emocional (Klaus \& Kennel, 1992) e que não há como passar pela experiência da gestação de forma indiferente (Maldonado, 1989). Além disso, a experiência da maternidade na adolescência tem um papel importante no desenvolvimento do adolescente. Porém, mesmo com a possibilidade de amadurecimento em alguns aspectos da vida, essa mãe continua sendo adolescente, e por isso pode ter algumas dificuldades nessa tarefa (Flanagan et al., 1995).

\section{Considerações finais}

O presente estudo buscou investigar a constelação da maternidade no contexto da gravidez na adolescência. Os resultados mostraram que aspectos da constelação da maternidade podem ser observados nesse contexto e que possuem semelhanças e também diferenças em relaço àqueles descritos por Stern (1997) e por outros estudos nacionais e internacionais. Os achados acerca do tema vida-crescimento corroboram os resultados de Lopes et al. (2005) ao entender que o parto é antecipado, durante a gravidez, sob a forma de expectativas, muitas vezes negativas. Isso gera grande ansiedade e insegurança quanto ao parto, sendo então uma preocupação mencionada por todas as participantes. Além disso, as gestantes adolescentes desse estudo relataram preocupações e dúvidas referentes à sua capacidade de desempenho enquanto mãe. Frizzo et al. (2005) também encontraram que, quando comparadas às expectativas de gestantes adultas, as gestantes adolescentes mostravam preocupações mais elevadas acerca do seu desempenho enquanto mãe.

A maior semelhança entre os achados desse estudo e os temas da constelação da maternidade relatados por Stern (Stern, 1997) é formação de uma matriz de apoio pelas gestantes adolescentes, de modo muito semelhante ao descrito pela literatura sobre mães e gestantes adultas. Os resultados mostraram que se sobressai a escolha de figuras femininas mais experientes em relação à maternidade, mas que também há a entrada do marido/namorado nessa rede, corroborando Stern (1997). No presente estudo, o marido/ 
namorado apareceram na matriz de apoio assumindo, inclusive, um papel de apoio emocional à gestante adolescente. Também se evidenciou a importância do pai/padrinho da adolescente durante a gestação, figura que não apareceu nos artigos e bibliografias revisados, sendo necessários novos estudos que investiguem o papel do novo avô na gestação e maternidade adolescente.

A diferença mais marcante da constelação da maternidade entre as gestantes adolescentes do presente estudo se deu no tema da reorganização da identidade. As mudanças descritas por Stern (1997) parecem não ter acontecido da mesma forma nas gestantes adolescentes. Os aspectos mais salientados nesse tema disseram respeito a uma reorganização e busca da identidade adolescente concomitante à passagem para o mundo adulto, com as tarefas da segunda individuação (Blos, 1996) ocorrendo simultaneamente às tarefas da terceira (Colarusso, 1999). Tal reorganização também parece estar vinculada a uma reorganização da identidade a nível social (Dadoorian, 1998, 2007).

Além desses resultados, foi observada uma dificuldade das adolescentes em construir expectativas acerca do bebê no tema relacionar-se primário, assim como nos outros temas. Como ainda estão na gestação, as preocupações referentes a esse tema estão ligadas às suas expectativas em relação à maternidade e ao bebê. Tal achado corrobora os resultados de Piccinini et al. (2003), que mostram que em comparação com gestantes adultas, as gestantes adolescentes tiveram maior dificuldade em descrever suas percepções sobre seu bebê. Essa falta de expectativas gera um alerta para a qualidade da interação mãe-bebê após o nascimento, já que as expectativas maternas sobre o bebê são cruciais para o estabelecimento desta relação também após o nascimento (Brazelton, 1987, 1988).

Intervenções com mães adolescentes devem, então, atentar à sobreposição de tarefas em seu ciclo de vida, o que pode lhes causar uma sobrecarga emocional e impactar o relacionamento inicial com o bebê. Além disso, há muitos estudos quantitativos sobre o tema da gravidez adolescente, mas poucos referem-se a aspectos mais subjetivos e emocionais dessas mães, aspectos esses que vão influenciar no estabelecimento do vínculo entre elas e os filhos.

\section{The motherhood constellation in teen pregnancy: A case study}

Abstract: The aim of this study was to investigate the motherhood constellation in the context of teenage pregnancy. We used a multiple-case study, which involved three pregnant teenagers, primiparous, who were in the third trimester of pregnancy. Qualitative content analysis was performed and data were categorized following the four themes of the motherhood constellation: life-growth, primary relatedness, support matrix and identity reorganization. Being pregnant, the issues related to the primary relatedness theme appeared strongly linked to their expectations of motherhood and the baby, but some participants demonstrated difficulties in creating such expectations. The most striking differences in the motherhood constellation among pregnant teenagers occurred on the theme of identity reorganization, in which the aspects highlighted told about the reorganization and adolescent search for identity concurrent with the transition to the adult world, and a reorganization of the social identity level.

Keywords: Teenage pregnancy, maternity, case study.

\section{La constellation de la maternité dans le contexte de la grossesse chez les adolescentes : une étude de cas}

Résumé: Le but de cette étude a été d'étudier la Constellation de la maternité dans le contexte de la grossesse chez les adolescentes. Nous avons utilisé une étude de conception collective de cas, avec la participation de trois adolescents enceintes de son premier enfant, qui étaient dans le troisième trimestre de la grossesse. Nous avons effectué une analyse de contenu qualitative des entrevues et les données ont été classées selon les quatre thèmes de la Constellation de la maternité : la vie et la croissance, le rapport primaire, la matrice d'appui la réorganisation d'identité. Pour être des femmes eenceintes, le thème du rapport primaire paraissait fortement liée à leurs attentes en matière de maternité et de bébé, mais certaines participantes ont démontré des difficultés dans la création de ces attentes. La différence la plus frappante de la constellation de la maternité chez les adolescentes enceintes a été le thème de la réorganisation de l'identité, dans lequel les aspects les plus soulignés faisaient référence à une réorganisation et une recherche d'identité adolescente concomitante à la transitions vers le monde adulte.

Mots-clés: grossesse chez les adolescentes, maternité, étude de cas.

\section{La constelación de la maternidad en el contexto del embarazo en la adolescencia: un estudio de casos}

Resumen: El objetivo de esta investigación fue investigar la constelación de la maternidad en el contexto del embarazo en la adolescencia. Se utilizó un diseño de estudio de caso colectivo, con la participación de tres adolescentes embarazadas de su 
primer hijo que se encontraban en el tercer trimestre del embarazo. Se realizó análisis de contenido cualitativo de las entrevistas y los datos fueron categorizados siguiendo los cuatro temas de la constelación maternal: la vida-crecimiento, la relación primaria, la matriz de soporte y la reorganización de identidad. Porque son mujeres embarazadas, las cuestiones relacionadas con el tema relación primaria aparecían fuertemente pegadas a sus expectativas en relación a la maternidad y al bebé, pero algunas participantes demostraron dificultades en la creación de tales expectativas. La diferencia más notable en la constelación de la maternidad de las adolescentes embarazadas se presentó en el tema de la reorganización de la identidad, en el cual los aspectos destacados se refirieron a una reorganización y a la búsqueda de la identidad de los adolescentes simultánea a la transición hacia el mundo adulto.

Palabras clave: Embarazo en la adolescencia, maternidad, estudio de caso.

\section{Referências}

Amazarray, M. R., Machado, P. S., Oliveira, V. Z., \& Gomes, W. B. (1998). A experiência de assumir a gestação na adolescência: um estudo fenomenológico. Psicologia: Reflexão e Crítica, 11(3), 431-440.

Amorim, M. M. R., Lima, L. A., Lopes, C. V., Araújo, D. K. L., Silva, J. G. G., César, L. C., \& Melo, A. S. O. (2009). Fatores de risco para a gravidez na adolescência em uma maternidade-escola da Paraíba: estudo caso-controle. Revista Brasileira de Ginecologia e Obstetrícia, 31, 404-410.

Bardin, L. (1977). Análise de conteúdo. Lisboa, Portugal: Edições 70

Baron, M. E., Broughton, D. D., Buttross, S., Corrigan, S., Gedissman, A., Rivas, M. R. G., Rich, M., \& Shifrin, D. L. (2001). Sexuality, contraception, and the media. Pediatrics, 107(1), 191-194.

Benincasa, M., Rezende, M. M., \& Coniaric, J. (2008). Sexo desprotegido e adolescência: fatores de risco e de proteção. Psicologia: Teoria e Prática, 10, 121-134.

Blos, P. (1994). Adolescência: uma interpretação psicanalítica. São Paulo, SP: Martins Fontes.

Blos, P. (1996). O segundo processo de individuação. In P. Blos (Ed.), Transição adolescente. Porto Alegre, RS: Artes Médicas.

Brazelton, T. (1987). O bebê: parceiro na interação. In T. Brazelton, B. Cramer, L. Kreisler, R. Schäppi \& M. Soulé (Eds.), A dinâmica do bebê (pp. 9-23). Porto Alegre, RS: Artes Médicas.

Brazelton, T. (1988). O desenvolvimento do apego. Porto Alegre: Artes Médicas.

Brazelton, T. B., \& Cramer, B. G. (1992). As primeiras relações. São Paulo, SP: Martins Fontes.

Brückner, H., Martin, A., \& Bearman, P. S. (2004). Ambivalence and pregnancy: Adolescents' attitudes, contraceptive use and pregnancy. Perspectives on Sexual and Reproductive Health, 36(6), 248-257.

Bunting, L., \& McAuley, C. (2004). Teenage pregnancy and motherhood: The contribution of support. Child and Family Social Work, 9, 207-215.

Cabral, S. A., \& Levandowski, D. C. (2011). Representações maternas: teóricos e possibilidades de avaliação e intervenção clínica. Estilos da Clínica, 16(1), 186-203.

Caron, N., Fonseca, M., \& Kompinsky, E. (2000). Aplicação da observação na ultra-sonografia obstétrica. In N. Caron (Ed.), A relação pais-bebê: da observação à clínica (pp. 178-206). São Paulo: Casa do Psicólogo.

Chalem, E., Mitsuhiro, S. S., Ferri, C. P., Barros, M. C. M., Guinsburg, R., \& Laranjeira, R. (2007). Gravidez na adolescência: perfil sócio-demográfico e comportamental de uma população da periferia de São Paulo, Brasil. Cadernos de Saúde Pública, 23, 177-186.

Colarusso, C. A. (1990). The third individuation: The effect of biological parenthood on separation-individuation processes in adulthood. Psychoanalitical Study of the Child, 45, 179-194.

Cramer, B. G., \& Palacio-Espasa, F. (1993). Técnicas psicoterápicas mãe/bebê. Porto Alegre, RS: Artes Médicas.

Cunnington, A. J. (2001). What's so bad about teenage pregnancy? The Journal of Family Planning and Reproductive Health Care, 27(1), 36-41.

Dadoorian, D. (1998). A gravidez desejada na adolescência. Arquivos Brasileiros de Psicologia, 50(31), 60-70.

Dadoorian, D. (2003). Gravidez na adolescência: um novo olhar. Psicologia: Ciência e Profissão, 23, 84-91.

Dias, A. B., \& Aquino, E. M. L.(2006). Maternidade e paternidade na adolescência: algumas constatações em três cidades do Brasil. Cadernos de Saúde Pública, 22, 1447-1458.

Dirani, C. C. (1993). Expectativas e sonhos da gestante na primeira gravidez (Dissertação de Mestrado). Universidade Federal do Rio Grande do Sul, Porto Alegre, RS.

Esteves, J. R., \& Menandro, P. R. M. (2005). Trajetórias de vida: repercussões da maternidade adolescente na biografia de mulheres que viveram tal experiência. Estudos de Psicologia, 10, 363-370.

Fernandes, A. O., Santos-Júnior, H. P. O., \& Gualda, D. M. R. (2012). Gravidez na adolescência: percepções das mães de gestantes jovens. Acta Paulista de Enfermagem, 25(1), 55-60.

Flanagan, P. J., McGrath, M. M., Meyer, E. C., \& Coll, C. T. G. (1995). Adolescent development and transitions to 
motherhood. Pediatrics, 96(2), 273-277.

Fraiberg, S., Adelson, E., \& Shapiro, V. (1994). Fantasmas no quarto do bebê: uma abordagem psicanalítica dos problemas que entravam a relação mãe-bebê. Revista do Ceapia, 7(7), 12-34.

Freitas, A. P. C. O. (2013). Tornar-se avó e a transmissão transgeracional no contexto da maternidade na adolescência (Tese de Doutorado). Universidade Federal do Rio Grande do Sul, Porto Alegre, RS.

Frizzo, G. B., Kahl, M. L. F., \& Oliveira, E. A. F. (2005). Aspectos psicológicos da gravidez na adolescência. PSICO, 36(1), 13-20.

Frizzo, G. B., Brys, I., Lopes, R. C. S., \& Piccinini, C. A. (2010). Conjugalidade em contexto de depressão da esposa no final do primeiro ano de vida do bebê. Aletheia, 66-81.

Frizzo, G. B., Prado, L. C., Linares, J. L., \& Piccinini, C. A. (2011). Aspectos relacionais da depressão: o conceito de "honorável fachada" em dois casos clínicos. Psicologia Clínica, 23, 133-155.

Gabriel, M. R., Ribeiro, F., Vivian, A., \& Lopes, R. C. S. (2012). Abrindo espaço para um segundo bebê: impacto na constelação da maternidade. (In press).

Gama, S. G. N., Szwarcwald, C. L., \& Leal, M. C. (2002). Experiência de gravidez na adolescência, fatores associados e resultados perinatais entre puérperas de baixa renda. Cadernos de Saúde Pública, 18, 153161.

George, C., \& Solomon, J. (1996). Representational models of relationships: Links between caregiving and attachment. Infant Mental Health Journal, 17(3), 198-216.

Godinho, R. A., Schelp, J. R. B., Parada, C. M. G. L., \& Bertoncello, N. M. F. (2000). Adolescentes e grávidas: onde buscam apoio? Revista Latino-americana de Enfermagem, 8(2), 25-32.

Golse, B. (2002). O que temos aprendido com os bebês. In L. C. Filho, M. E. G. Corrêa \& P.S. França (Eds.), Novos olhares sobre a gestação e a criança de 0 a 3 anos: Saúde perinatal, educação e desenvolvimento do bebê. Brasília, DF: L. G. E. Editora.

Ilicali, E. T., \& Fisek, G. O. (2004). Maternal representations during pregnancy and early motherhood. Infant Mental Health Journal, 25(1), 16-27.

Imamura, M., Tucker, J., Hannaford, P., Silva, M. O., Astin, M., Wyness, L., Bloemenkamp, K. W., Jahn, A., Karro, H., Olsen, J., \& Temmerman, M. (2007). Factors associated with teenage pregnancy in the European Union countries: A systematic review. European Journal of Public Health, 17(6), 630-636.

Inhelder, B., \& Piaget, J. (1976). O pensamento do adolescente. In B. Inhelder \& J. Piaget (Eds.), Da lógica da criança à lógica do adolescente (pp. 249-260). São Paulo, SP: Pioneira.

Innamorati, M., Sarracino, D., \& Dazzi, N. (2010). Motherhood constellation and representational change in pregnancy. Infant Mental Health Journal, 31(2), 319396.
Klaus, M. \& Kennel, J. (1992). Pais/bebê: a formação do apego. Porto Alegre, RS: Artes Médicas.

Klaus, M. H., Kennell, J. H., \& Klaus, P. H. (2000). Vinculo:construindo as bases para um apego seguro $e$ para a independência (M. R. Hofmeister, trad.). Porto Alegre, RS: Artes Médicas.

Knobel, M. (1981). A síndrome da adolescência normal. In A. Aberastury \& M. Knobel (Eds.), Adolescência normal: um enfoque psicanalítico (pp. 2-4). Porto Alegre, RS: Artes Médicas.

Lage, A. M. D. (2008). Vivências da gravidez de adolescentes (Tese de Doutorado). Universidade Federal de Minas Gerais, Belo Horizonte, MG.

Laville, C., \& Dionne, J. (1999). A construção do saber. Porto Alegre, RS: Artes Médicas.

Levandowski, D. C., Barth, B., Munhós, A. A. R., Rödde, A. C., \& Wendland, J. (2012). Apoio familiar e gestação na adolescência: um estudo qualitativo com adolescentes do Vale dos Sinos/BR. Revista Interamericana de Psicología, 46(2), 297-306.

Levandowski, D. C., Piccinini, C. A., \& Lopes, R. C. S. (2008). Maternidade adolescente. Estudos de Psicologia, 25, 251-263.

Levandowski, D. C., Piccinini, C. A., \& Lopes, R. C. S. (2009). O Processo de separação-individuação em adolescentes do sexo masculino na transição para a paternidade. Psicologia: Reflexão e Crítica, 22, 353-361.

Lopes, R. C. S., Prochnow, L. P., \& Piccinini, C. A. (2010). A relação da mãe com suas figuras de apoio femininas e os sentimentos em relação à maternidade. Psicologia em Estudo, 15, 295-304.

Lopes, R. C. S., Donelli, T. S., Lima, C. M., \& Piccinini, C. A. (2005). O antes e o depois: expectativas e experiências de mães sobre o parto. Psicologia: Reflexão e Crítica, 18(2), 247-254.

Maldonado, M. T. (1989). Maternidade e paternidade (Vol. 2). Petrópolis, RJ: Vozes.

Miller, R. J., \& Darlington, Y. (2002). Who supports: The providers of social support to dual-parent families caring for young children. Journal of Community Psychology, 30(5), 461-473.

Núcleo de Infância e Família - NUDIF. (2008a). Entrevista sobre a gravidez adolescente no terceiro trimestre de gestação. Instituto de Psicologia - UFRGS. Porto Alegre, RS. (Instrumento não-publicado)

Núcleo de Infância e Família - NUDIF (2008b). Entrevista de dados sócio-demográficos. Instituto de Psicologia - UFRGS. Porto Alegre, RS. (Instrumento nãopublicado)

Osório, L. C. (1989). Adolescência hoje. Porto Alegre, RS: Artmed.

Outeiral, J. O. (1994). Adolescer: estudos sobre adolescência. Porto Alegre, RS: Artes Médicas.

Pariz, J., Mengarda, C. F., \& Frizzo, G. B. (2012). A atenção e o cuidado à gravidez na adolescência nos âmbitos familiar, político e na sociedade: uma revisão da literatura. Saúde e Sociedade, 21(3), 623-636. 
Piccinini, C. A., Ferrari, A. G., Levandowski, D. C., Lopes, R. C. S., \& Nardi, T. C. (2003). O bebê imaginário e as expectativas quanto ao futuro do filho em gestantes adolescentes e adultas. Interações, 8, 81-108.

Piccinini, C. A., Gomes, A. G., Moreira, L. E., \& Lopes, R. S. (2004). Expectativas e sentimentos da gestante em relação ao seu bebê. Psicologia: Teoria e Pesquisa, 20(3), 223-232.

Piccinini, C. A., Lopes, R. C. S., Gomes, A. G., \& De Nardi, T. (2008). Gestação e a constituição da maternidade. Psicologia em Estudo, 13, 63-72.

Piccinini, C. A., Lopes, R. C. S., Marin, A. H., Carvalho, F. T., Henn, C. G., \& Dias, A. C. G., (2008b). Aspectos biopsicossociais da gravidez adolescente: estudo longitudinal da gestação ao segundo ano de vida da criança. Instituto de Psicologia - UFRGS. Porto Alegre, RS. (Projeto de Pesquisa não publicado)

Schwartz, T., Vieira, R., \& Geib, L. T. C. (2011). Apoio social a gestantes adolescentes: desvelando percepções. Ciência \& Saúde Coletiva, 16, 2575-2585.

Schwenberger, D. D. S., \& Piccinini, C. A. (2003). O impacto da depressão pós-parto para a interação mãebebê. Estudos de Psicologia, 8(3), 403-411.

Schwengber, D. D. S., Prado, L. C., \& Piccinini, C. A. (2009). O impacto de uma psicoterapia breve pais-bebê para as representações acerca da maternidade no contexto da depressão. PSICO, 40(3), 382-391.
Singh, S., \& Darroch, J. E. (2000). Adolescent pregnancy and childbearing: Levels and trends in developed countries. Family planning perspective, 32, $14-23$.

Stake, R. E. (1994). Case studies. In N. Denzin \& Y. Lincoln (Eds.), Handbook of Qualitative Research (pp. 236-247). Londres: Sage.

Stern, D. (1997). A constelação da maternidade: o panorama da psicoterapia pais-bebê (M. V. A. Veronese, trad.). Porto Alegre, RS: Artes Médicas.

Teixeira, I. T., \& Leal, I. P.(2008). Expectativas e atitudes de mães primíparas com filhos prematuros. Notas de investigação, 191-194.

Wendland, J. (2001). A abordagem clínica das interações pais-bebê: perspectivas teóricas e metodológicas. Psicologia: Reflexão e Crítica, 14(1), 45-56.

Winnicott, D. W. (1985). E o pai? In D. W. Winnicott (Ed.), A criança e o seu mundo (pp. 127-133). Rio de Janeiro, RJ: Zahar.

Ximenes Neto, F. R. G., Dias, M. S. A., Rocha, J., \& Cunha, I. C. K. O. (2007). Gravidez na adolescência: motivos e percepções de adolescentes. Revista Brasileira de Enfermagem, 60, 279-285.

Zornig, S. M. A. J. (2010). Tornar-se pai, tornar-se mãe: o processo de construção da parentalidade. Tempo Psicanalitico, 42, 453-470. 